\title{
COMPACTAÇÃO DE SOLOS CULTIVADOS COM CANA-DE-AÇÚCAR: I - MODELAGEM E QUANTIFICAÇÃO DA COMPACTAÇÃO ADICIONAL APÓS AS OPERAÇÕES DE COLHEITA ${ }^{1}$
}

\author{
EDUARDO DA C. SEVERIANO ${ }^{2}$, GERALDO C. DE OLIVEIRA ${ }^{3}$, \\ MOACIR DE S. DIAS JÚNIOR ${ }^{4}$, MATHEUS B. DE CASTRO ${ }^{5}$, LUIZ F. C. DE OLIVEIRA ${ }^{6}$, \\ KATIA A. DE P. COSTA ${ }^{7}$
}

\begin{abstract}
RESUMO: A colheita mecanizada da cana-de-açúcar, quando realizada em épocas da safra em que o solo se encontra com conteúdos inadequados de água, tem sido responsável pela compactação do solo e a redução da produtividade nos ciclos posteriores da cultura. Este estudo teve como objetivo avaliar o efeito das operações de colheita da cana-de-açúcar em diferentes épocas da safra sobre a pressão de preconsolidação em um Latossolo Vermelho-Amarelo (LVA) e em um Cambissolo Háplico (CX). A colheita mecanizada consistiu no tráfego de duas passadas de uma colhedora de cana e do conjunto trator + transbordo em cada entrelinha da cultura. As amostras indeformadas foram utilizadas na determinação dos modelos de capacidade de suporte de carga do solo e na quantificação da compactação em decorrência da colheita mecanizada nos meses de novembro de 2005, março e agosto de 2006, e colheita manual sem tráfego, em março de 2006, por ser a época de maior intensidade pluvial. A porcentagem de amostras de solo, na região onde ocorre compactação adicional, indicou que o CX foi mais resistente à compactação que o LVA. A colheita mecanizada da cana-de-açúcar, mesmo sendo realizada na zona de friabilidade, causou compactação do solo, enquanto a colheita realizada manualmente não promoveu o mesmo efeito.
\end{abstract}

PALAVRAS-CHAVE: Saccharum sp., mecanização da colheita, pressão de preconsolidação, capacidade de suporte de carga do solo.

\section{COMPACTION OF SOILS CULTIVATED WITH SUGARCANE: I - MODELING AND QUANTIFICATION OF THE ADDITIONAL SOIL COMPACTION AFTER HARVEST OPERATIONS}

ABSTRACT: The mechanized harvesting of sugarcane when accomplished in times of crop where the soil meets the inappropriate water contents has been responsible for soil compaction and reduction of yield in subsequent cycles of the crop. This study aimed to evaluate the effect of the harvesting operations of sugarcane at different times of the crop on preconsolidation pressure in a Red-Yellow Latosol (LVA) and in a Haplic Cambisol (CX). Mechanized harvesting traffic consisted of two passes of a sugarcane harvester and tractor + sugarcane transfer in each interrow of the culture. Undisturbed soil samples were used to determine the soil bearing capacity models and quantification of soil compaction due to mechanical harvesting in the months of November 2005, March and August 2006, and manual harvesting without traffic, in March 2006, because it is a time of greater rainfall intensity. The percentage of soil samples, in the region where additional soil compaction occurs, indicated that the CX was more resistant to compaction than the LVA. A mechanized harvesting of sugarcane being held in the friability zone caused soil compaction while the harvest accomplished manually did not cause the same effect.

KEYWORDS: Saccharum sp., mechanized harvesting, preconsolidation pressure, soil bearing capacity.

\footnotetext{
${ }^{1}$ Extraído da dissertação de mestrado do primeiro autor. Projeto financiado pelo CNPq e Empresa Jalles Machado S.A.

${ }^{2}$ Eng ${ }^{\mathrm{o}}$ Agrônomo, Bolsista de Desenvolvimento Científico Regional (FAPEG/CNPq), Instituto Federal de Educação, Ciência e Tecnologia Goiano, Campus Rio Verde, Rio Verde - GO, Fone (0XX64) 3620.5636, severianoec@ yahoo.com.br.

${ }^{3}$ Eng $^{\mathrm{o}}$ Agrícola, Professor Adjunto, Departamento de Ciência do Solo (DCS), Universidade Federal de Lavras (UFLA), Lavras MG, geraldooliveira@dcs.ufla.br, Bolsista CAPES - Tutor PET Agronomia da UFLA.

${ }^{4}$ Eng- ${ }^{-}$Agrícola, Professor Associado, DCS/UFLA, msouzadj@dcs.ufla.br, Bolsista do CNPq.

${ }^{5}$ Eng ${ }^{\text {o }}$ Agrônomo, Mestrando em Fitotecnia, Departamento de Agricultura, DAG/UFLA, matheusbcastro87@ hotmail.com.

${ }^{6}$ Eng $^{\mathrm{O}}$ Agrícola, Professor Associado, Departamento de Engenharia, DEG/UFLA. Bolsista do CNPq.

${ }^{7}$ Professora do Programa de Pós-Graduação em Produção Vegetal, Universidade de Rio Verde (FESURV), Rio Verde - GO.

Recebido pelo Conselho Editorial em: 17-4-2009
}

Aprovado pelo Conselho Editorial em: 12-12-2009 


\section{INTRODUÇÃO}

A aceitação internacional do etanol como combustível e a lucratividade alcançada pelo setor sucroalcooleiro têm trazido euforia aos produtores de cana-de-açúcar, com reflexos na intensificação e na expansão do seu cultivo. Dentre os fatores de produção relacionados com a modernização da canavicultura brasileira, destaca-se o crescimento da demanda pela colheita mecanizada (SOUZA et al., 2005). Entretanto, o tráfego de máquinas vem promovendo alterações nas propriedades físicas dos solos e intensificando o processo de compactação dos mesmos (CAMILOTTI et al., 2005), trazendo como consequências a queda de produtividade da cultura e o aumento dos processos erosivos (OLIVEIRA et al., 2004).

Na região Centro-Sul do Brasil, a safra canavieira estende-se de abril a outubro (HORII, 2004), período que se caracteriza como sendo de baixa intensidade pluvial. Por outro lado, observa-se uma tendência de redução do período de entressafra (SEVERIANO et al., 2009), o que condiciona tráfego de máquinas para colheita em condições de elevados conteúdos de água no solo. Em condições inadequadas para o tráfego, a sustentabilidade agrícola e ambiental pode ser colocada em risco, por comprometer diretamente a qualidade estrutural do solo (OLIVEIRA et al., 2003).

A compactação dos solos em agrossistemas canavieiros tem sido atribuída principalmente à colheita mecanizada em condições de elevados conteúdos de água no solo (PANKHURST et al., 2003). Assim, a determinação da umidade do solo antes da realização das operações mecanizadas torna-se indispensável, pelo fato de essa governar a capacidade de suporte de carga do solo (KONDO \& DIAS JÚNIOR, 1999).

Os recentes estudos de modelagem da compactação de solos agrícolas (DIAS JÚNIOR et al., 2005; SILVA et al., 2007), bem como o conhecimento da capacidade de suporte de carga das diferentes classes de solo (DIAS JÚNIOR et al., 2007), e da quantificação dos efeitos do tráfego em diferentes períodos da safra canavieira podem tornar-se a base necessária para a minimização dos impactos na estrutura dos solos cultivados com cana-de-açúcar.

O objetivo deste trabalho foi avaliar o efeito das operações de colheita da cana-de-açúcar em diferentes épocas da safra sobre a compactação de um Latossolo Vermelho-Amarelo e de um Cambissolo Háplico, no município de Goianésia - GO.

\section{MATERIAL E MÉTODOS}

O estudo foi conduzido nas áreas experimentais pertencentes à empresa Jalles Machado S.A., localizada no município de Goianésia - GO, a $15^{\circ} 10^{\prime} \mathrm{S}$ de latitude e $49^{\circ} 15^{\prime} \mathrm{W}$ de longitude e $640 \mathrm{~m}$ de altitude. O clima é classificado, segundo Köeppen, como tropical de savana, quente e úmido, com inverno seco e verão chuvoso (Aw) e média pluvial anual de $1.500 \mathrm{~mm}$.

$\mathrm{Na}$ condução deste estudo, selecionaram-se áreas experimentais em um Latossolo Vermelho-Amarelo (LVA) e em um Cambissolo Háplico (CX) (EMBRAPA, 2006). De acordo com SEVERIANO et al. (2009), as terras onde se insere o LVA pertencem à classe de capacidade de uso IIIs, tendo como maior limitação a baixa fertilidade natural, e as terras do CX à classe IV e, sendo, nesse caso, a declividade o fator mais limitante.

Em março de 2004, por ocasião da renovação do canavial, após a rotação de cultura utilizando a soja, as áreas foram submetidas ao preparo do solo com as operações de aração e gradagens. Os solos foram sulcados, adubados e, na sequência, foi realizado o plantio da cana-de-açúcar. Em setembro de 2005, foram demarcados, em cada área, três blocos contendo quatro parcelas com dimensões de $10 \mathrm{~m}$ de comprimento e $14 \mathrm{~m}$ de largura, com 10 linhas de cana-de-açúcar espaçadas em 1,40 m. Nessa ocasião, realizou-se a descrição morfológica do solo segundo SANTOS et al. (2005).

Antes das operações de colheita da cana-de-açúcar, foram feitas amostragens de solo em três pontos de uma linha diagonal dentro de cada parcela, distantes 6,6 $\mathrm{m}$ uma das outras. Foram 
coletadas, a $70 \mathrm{~cm}$ de distância das linhas da cana-de-açúcar (centro da entrelinha), seis amostras de solo indeformadas em anéis de alumínio com $6,40 \mathrm{~cm}$ de diâmetro e 2,50 cm de altura por parcela, na profundidade de 0 a $5 \mathrm{~cm}$, totalizando 144 amostras ( 6 amostras x 12 parcelas x 2 solos), as quais foram envolvidas com uma camada de parafina no campo para a manutenção do seu conteúdo de água.

As amostras deformadas, correspondentes à profundidade de 0 a $5 \mathrm{~cm}$, foram obtidas pela coleta do solo das porções superiores e inferiores das amostras indeformadas, formando uma amostra composta em cada parcela, para a realização das análises de caracterização química e física do solo e determinação dos limites de contração (LC), plasticidade (LP) e liquidez (LL) dos solos, segundo proposto por EMBRAPA (1997). Foram coletadas também quatro amostras deformadas, nas profundidades de 60 a $80 \mathrm{~cm}$ e 40 a $60 \mathrm{~cm}$, correspondentes aos horizontes diagnósticos Bw e Bi do LVA e CX, respectivamente, utilizadas nas análises de caracterização e classificação dos mesmos.

Na determinação das curvas de retenção de água no solo, 12 amostras indeformadas de cada solo foram saturadas e submetidas às tensões matriciais de $2 ; 4 ; 6$ e $10 \mathrm{kPa}$ na coluna de areia (REINERT \& REICHERT, 2006) e 33; 60; 80; 100; 500 e $1.500 \mathrm{kPa}$ nos aparelhos extratores de Richards (EMBRAPA, 1997). As demais amostras indeformadas foram equilibradas, por meio de secagem natural, segundo KONDO \& DIAS JÚNIOR (1999), a conteúdos de água variando entre os teores correspondentes às tensões de 2 a $1.500 \mathrm{kPa}$, sendo, então, submetidas ao ensaio de compressão uniaxial (DIAS JÚNIOR, 1994).

As pressões aplicadas em cada amostra obedeceram à seguinte ordem: 25;50;100;200;400; 800 e $1.600 \mathrm{kPa}$, sendo cada uma delas aplicada até que se atingisse $90 \%$ da deformação máxima (TAYLOR, 1948) e somente então foi aplicada uma nova pressão. A pressão de preconsolidação $\left(\sigma_{\mathrm{p}}\right)$ foi obtida segundo DIAS JÚNIOR \& PIERCE (1995).

Os tratamentos consistiram nas épocas e modalidade de colheita da cana-de-açúcar. Para essa avaliação, submeteram três parcelas em cada experimento à colheita mecanizada, com o tráfego de duas passadas em cada entrelinha da cultura, do seguinte maquinário: colhedora de cana de pneus Cameco, modelo CWH 2500 B, com tara de 16,5 Mg, trator John Deere, modelo 6605, com tara de 4,5 Mg e transbordo Cameco, modelo SMR 8500, com tara de 6,4 Mg, carregados com $8 \mathrm{Mg}$ de cana picada.

As colheitas foram realizadas nos meses de novembro de 2005, março e agosto de 2006, possibilitando que os solos se encontrassem em diferentes conteúdos de água, por ocasião dessa operação. Para efeito comparativo dos impactos da colheita mecanizada da cana-de-açúcar na degradação da estrutura do solo, realizou-se a colheita manual de cana crua, sem tráfego de máquinas, em março de 2006, por ser essa a época da safra de maior intensidade pluvial na região.

Após a colheita da cana-de-açúcar, coletaram-se amostras indeformadas e procedeu-se à determinação do conteúdo de água no solo, segundo metodologia proposta pela EMBRAPA (1997) e ensaios de compressão uniaxial, conforme descrito anteriormente. Para a obtenção das curvas de retenção de água do solo, os conteúdos de água, obtidos gravimetricamente (U), foram ajustados de acordo com a tensão da água no solo $\left(\psi_{\mathrm{m}}\right)$ ao modelo proposto por GENUCHTEN (1980) com o uso do software SWRC (DOURADO NETO et al., 2001).

Os modelos de capacidade de suporte de carga dos solos foram obtidos ajustando-se a $\sigma_{\mathrm{p}} \mathrm{em}$ função do conteúdo de água no solo (U), conforme DIAS JÚNIOR (1994), e as comparações das regressões foram feitas segundo SNEDECOR \& COCHRAN (1989). Determinou-se o intervalo de confiança, a 95\%, dos modelos de capacidade de suporte de carga, e as três regiões propostas por DIAS JÚNIOR et al. (2005) foram utilizadas no monitoramento da compactação dos solos em decorrência das operações de colheita da cana-de-açúcar. 


\section{RESULTADOS E DISCUSSÃO}

Os valores de $\mathrm{Kr}$ superiores a 0,75, nos dois solos (Tabela 1), indicam que os solos apresentam semelhanças mineralógicas. Há também grande semelhança granulométrica entre os solos (Tabela 1). Como a mineralogia, a textura e a estrutura são citadas por LEBERT \& HORN (1991), como fatores intrínsecos do solo que influenciam no processo de compactação do solo e tendo em vista a semelhança dos solos em relação aos dois primeiros atributos, sugere-se forte participação do tamanho, classe e grau de estruturação dos solos no processo de compactação dos mesmos, uma vez que esses parâmetros são responsáveis pelo número de pontos de contato entre as partículas do solo.

TABELA 1. Caracterização química e física do Latossolo Vermelho-Amarelo (LVA) e do Cambissolo Háplico (CX), cultivados com cana-de-açúcar. Chemical and physical characterization of the Red-Yellow Latosol (LVA) and the Haplic Cambisol (CX), cultivated with sugarcane.

\begin{tabular}{|c|c|c|c|c|c|c|c|c|c|}
\hline \multirow{2}{*}{$\begin{array}{l}\text { Prof. }^{1} \\
(\mathrm{~cm})\end{array}$} & \multirow{2}{*}{$\mathrm{Dp}^{2}$} & $\mathrm{Ds}^{3}$ & $\mathrm{MO}^{4}$ & \multicolumn{4}{|c|}{ Granulometria $^{5}$} & \multirow[b]{2}{*}{$\mathrm{Ki}^{4}$} & \multirow[b]{2}{*}{$\mathrm{Kr}^{4}$} \\
\hline & & $---\left(\mathrm{kg} \mathrm{dm}^{-3}\right)---$ & - & A & $\begin{array}{c}\mathrm{S} \\
\left.\mathrm{kg}^{-1}\right)\end{array}$ & $\mathrm{AF}$ & AG & & \\
\hline \multicolumn{10}{|c|}{ Latossolo Vermelho-Amarelo (LVA) } \\
\hline $0-5$ & 2,64 & 1,37 & 15 & 301 & 105 & 532 & 62 & - & - \\
\hline $60-80$ & 2,70 & 1,32 & 8 & 352 & 132 & 458 & 58 & 1,27 & 1,08 \\
\hline \multicolumn{10}{|c|}{ Cambissolo Háplico (CX) } \\
\hline $0-5$ & 2,67 & 1,29 & 26 & 266 & 206 & 489 & 39 & - & - \\
\hline $40-60$ & 2,68 & 1,26 & 14 & 323 & 209 & 434 & 34 & 1,32 & 1,03 \\
\hline
\end{tabular}

${ }^{1}$ - Profundidades correspondentes à camada superficial e horizonte B diagnóstico dos solos. ${ }^{2}$ - Dp: densidade de partículas pelo método do picnômetro; ${ }^{3}$ - Ds: densidade do solo inicial; ${ }^{4}$ - MO: matéria orgânica; ${ }^{5}$ - determinada pelo método da pipeta; A: argila; S: silte; AF: areia fina; AG: areia grossa; Ki: relação molecular $\mathrm{SiO}_{2}: \mathrm{Al}_{2} \mathrm{O}_{3}$; Kr: relação molecular $\mathrm{SiO}_{2}$ : $\left(\mathrm{Al}_{2} \mathrm{O}_{3}+\mathrm{Fe}_{2} \mathrm{O}_{3}\right)(\mathrm{média} \mathrm{de}$ 12 repetições).

O CX apresentou maior retenção de água (Figura 1), em função do maior ajuste entre as suas partículas, o que, segundo SEVERIANO et al. (2009), leva ao aumento das tensões de água no solo. Esse comportamento é observado particularmente nas tensões baixas e intermediárias, ao passo que sob altas tensões, há tendência de as curvas de retenção de água se aproximarem, devido à semelhança textural e mineralógica dos solos (CENTURION \& ANDRIOLI, 2000) (Tabela 1).

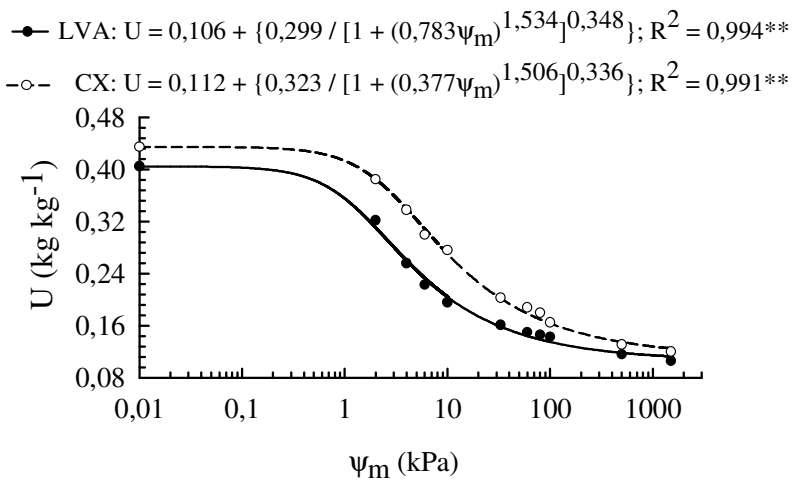

FIGURA 1. Curva de retenção de água de um Latossolo Vermelho-Amarelo (LVA) e um Cambissolo Háplico (CX) à profundidade de 0-5 cm, cultivados com cana-de-açúcar. Water retention curve of a Red-Yellow Latosol (LVA) and a Haplic Cambisol (CX), at 0-5 cm depth, cultivated with sugarcane. 
A utilização dos procedimentos estatísticos de SNEDECOR \& COCHRAN (1989) mostrou diferenças entre o comportamento compressivo dos solos (não homogêneo para as regressões; $\mathrm{F}=50,17 ; \mathrm{p}<0,001$ para o coeficiente linear, e $\mathrm{F}=134,80 ; \mathrm{p}<0,001$ para o coeficiente angular). A maior capacidade de suporte de carga do CX, observada na Figura 2, provavelmente se deve ao maior teor de matéria orgânica (Tabela 1) e ao maior ajuste entre e dentro dos agregados de tamanho pequeno a médio no formato de blocos com grau de coesão moderado a forte, em comparação à estrutura do LVA, que é formada também de agregados pequenos a médios no formato de blocos, mas que se desfazem em grânulos muito pequenos e com forte grau de coesão, ambos na camada de 0 a $5 \mathrm{~cm}$ (SANTOS et al., 2005). Essa característica confere ao Latossolo maior possibilidade de ajustes das partículas do solo quando submetido à compressão decorrente do tráfego de máquinas. Esses resultados corroboram aqueles encontrados por SILVA et al. (1999) em classes de solos semelhantes às do estudo.

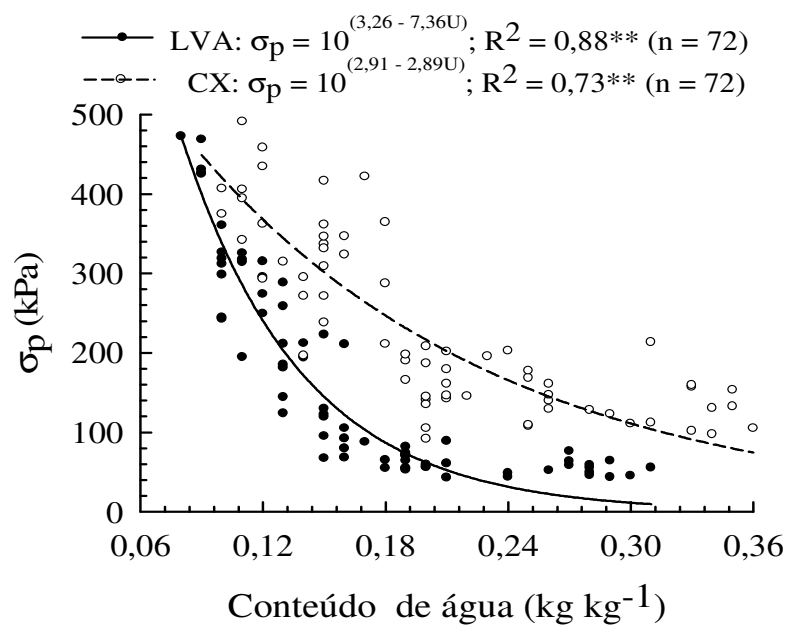

FIGURA 2. Modelos de capacidade de suporte de carga de um Latossolo Vermelho-Amarelo (LVA) e de um Cambissolo Háplico (CX), cultivados com cana-de-açúcar. Bearing capacity models of a Red-Yellow Latosol (LVA) and a Haplic Cambisol (CX), cultivated with sugarcane, at 0-5 cm depth.

Se, por um lado, o CX apresenta maior resistência à compactação, quantificada pelos maiores valores de $\sigma_{\mathrm{p}}$ (Figura 2), também apresenta maior retenção de água (Figura 1), sendo necessária grande cautela quanto ao melhor momento para a realização das operações mecanizadas, a fim de se evitar sua degradação estrutural (KONDO \& DIAS JÚNIOR, 1999), uma vez que, mesmo em épocas de menor intensidade pluvial, o mesmo poderá encontrar-se em conteúdos de água no solo superior ao LVA.

Particularmente sob altos conteúdos de água no Latossolo, os valores de capacidade de suporte de carga podem ser considerados baixos, o que pode ser atribuído ao fato de o preparo desse solo, por ocasião da renovação do canavial, ter provocado alívio das forças de coesão das partículas, em função da eliminação do histórico de uso do solo (VEIGA et al., 2007). Salienta-se, entretanto, que os dois solos sofreram o mesmo preparo.

Preconiza-se que a mecanização dos solos seja realizada quando seu conteúdo de água for correspondente à zona de friabilidade $(\mathrm{ZF})$, definida como o intervalo entre o conteúdo de água no limite de contração (LC) e o limite de plasticidade (LP). Observa-se que o CX (Figura 3B) apresenta maior ZF em relação ao LVA (Figura 3A) e, nesta faixa de água no solo, sua capacidade de suporte de carga variou de 262 a $165 \mathrm{kPa}$, enquanto, no LVA, variou de 170 a $86 \mathrm{kPa}$ (Figura 2). 
(A)

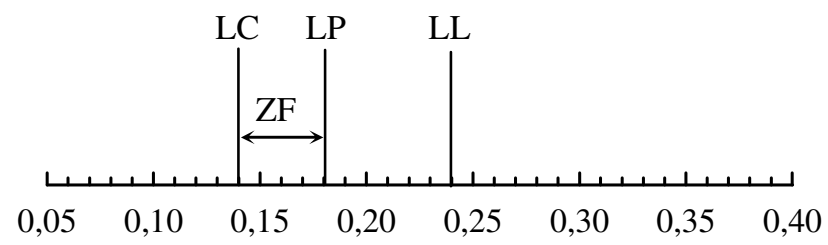

Conteúdo de água $\left(\mathrm{kg} \mathrm{kg}^{-1}\right)$

(B)

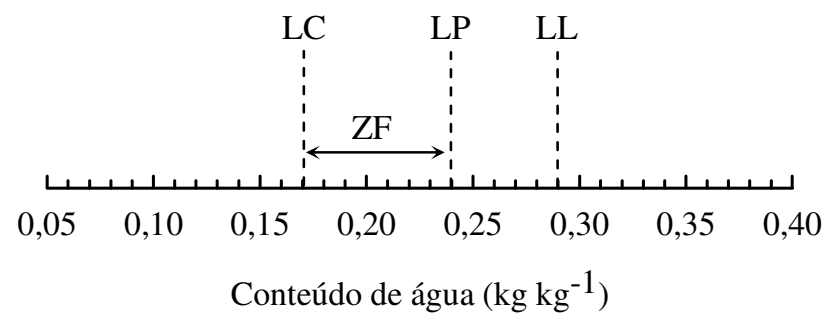

FIGURA 3. Limites de contração (LC), plasticidade (LP) e liquidez (LL) e zona de friabilidade (ZF) de um (A) Latossolo Vermelho-Amarelo (LVA) e de um (B) Cambissolo Háplico (CX), cultivados com cana-de-açúcar. Shrinkage (LC), plastic (LP) and liquid limits (LL) and friabilility zone (ZF) of a (A) Red-Yellow Latosol (LVA) and a (B) Haplic Cambisol (CX), cultivated with sugarcane.

A realização da colheita da cana-de-açúcar, em diferentes períodos da safra canavieira, condicionou o tráfego das máquinas também em diferentes conteúdos de água no solo (Tabela 2). Para as épocas avaliadas, no mês de novembro de 2005, os solos encontravam-se na ZF, sendo essa a condição recomendada para o tráfego de máquinas (KONDO \& DIAS JÚNIOR, 1999), e em agosto de 2006, abaixo dessa faixa (Figura 3). Em março de 2006, o solo encontrava-se com conteúdo de água acima da faixa da $\mathrm{ZF}$, considerada inadequada para o tráfego.

TABELA 2. Conteúdo de água no solo por ocasião da colheita da cana-de-açúcar, na profundidade de 0-5 cm, do Latossolo Vermelho-Amarelo (LVA) e do Cambissolo Háplico (CX). Soil water content at harvest of sugarcane, at 0-5 cm depth, of the Red-Yellow Latosol (LVA) and the Haplic Cambisol (CX) ${ }^{1}$.

\begin{tabular}{|c|c|c|c|c|}
\hline \multirow[b]{2}{*}{ Solo } & \multicolumn{3}{|c|}{ Colheita Mecanizada } & \multirow{2}{*}{$\begin{array}{c}\text { Colheita Manua } \\
03 / 2006^{3}\end{array}$} \\
\hline & $11 / 2005^{2}$ & $3 / 2006^{3}$ & $8 / 2006^{4}$ & \\
\hline & \multicolumn{4}{|c|}{--------- Conteúdo gravimétrico de água no solo $\left(\mathrm{kg} \mathrm{kg}^{-1}\right)$--------- } \\
\hline LVA & $0,16( \pm 0,0024)$ & $0,19( \pm 0,0024)$ & $0,11( \pm 0,0047)$ & $0,19( \pm 0,0024)$ \\
\hline $\mathrm{CX}$ & $0,22( \pm 0,0024)$ & $0,26( \pm 0,0024)$ & $0,16( \pm 0,0024)$ & $0,26( \pm 0,0024)$ \\
\hline
\end{tabular}

Para a avaliação dos efeitos decorrentes do tráfego de máquinas durante a colheita da cana-de-açúcar sobre a pressão de preconsolidação, a Figura 2 foi dividida em três regiões, de acordo com DIAS JÚNIOR et al. (2005) e apresentada na Figura 4. Na região "a”, a compactação adicional já ocorreu. Na região "b", indica que não ocorreu compactação adicional do solo, porém há uma tendência dessa ocorrência se as próximas operações mecanizadas excederem a capacidade de suporte de carga do solo, e a região "c" é aquela onde não ocorreu compactação do solo.

Observa-se (Tabela 3) que, em março de 2006, o mês mais crítico em termos de umidade do solo, $100 \%$ das amostras retiradas do Latossolo sob colheita mecanizada apresentaram compactação adicional contra apenas $50 \%$ das amostras do Cambissolo, mesmo este último solo estando com conteúdo de umidade $37 \%$ acima do primeiro. 
(A)
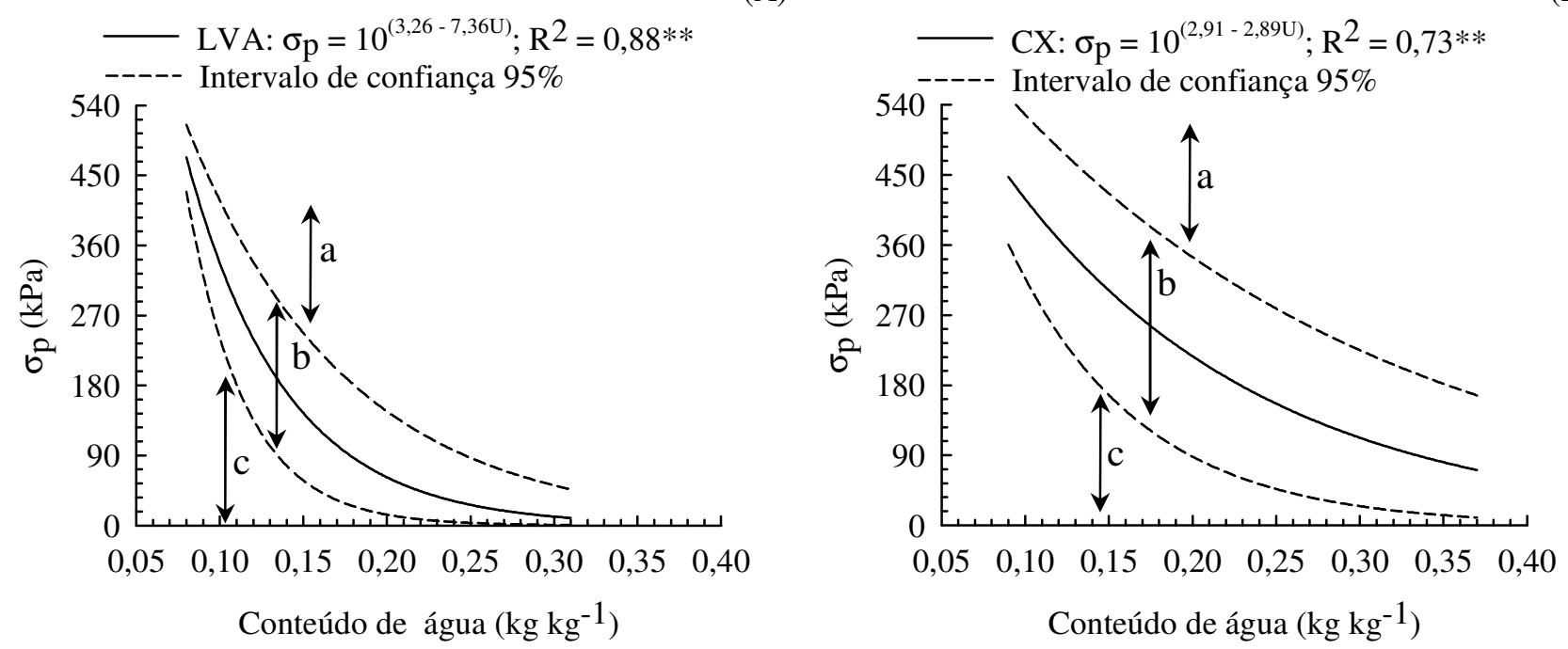

(B)

FIGURA 4. Modelos de capacidade de suporte de carga de um Latossolo Vermelho-Amarelo (LVA) (A) e de um Cambissolo Háplico (CX) (B), e critérios utilizados para analisar os efeitos das operações de colheita da cana-de-açúcar. Região "a": com compactação adicional; "b": com tendência a compactar, e "c": sem compactação. Bearing capacity models of a (A) Red-Yellow Latosol (LVA) and a (B) Haplic Cambisol (CX), and criteria used to assess the effects of harvesting operations of sugarcane. "a": region with additional soil compaction, "b": with a tendency to compact and $e$ "c": with no soil compaction.

Apesar dos maiores conteúdos de água no $\mathrm{CX}$ em todas as épocas de colheita, a porcentagem de compactação adicional no mesmo foi igual ou inferior à do LVA, sugerindo maior liberdade de tráfego, em épocas chuvosas da safra canavieira (condições de antecipação de safra), sobre o Cambissolo, em comparação ao Latossolo. Por outro lado, a colheita manual realizada neste mesmo mês não provocou alterações na estrutura dos solos estudados, já que $100 \%$ das amostras apresentaram apenas tendência de compactação (Tabela 3).

Ressalta-se a ocorrência de compactação adicional nos dois solos, no mês de novembro de 2005, ocasião em que o conteúdo de água, em ambos, encontrava-se dentro da ZF (Figura 3), confirmando o alerta apontado por KONDO \& DIAS JÚNIOR (1999) e OLIVEIRA et al. (2003) sobre a possibilidade de ocorrência de compactação, mesmo o solo sendo trabalhado nesse intervalo de umidade.

Sugere-se, portanto, além da modelagem da compactação de diferentes classes de solos, a necessidade de adoção de medidas preventivas para se evitar a compactação do solo no manejo da colheita mecanizada da cana-de-açúcar, como controle do nível de pressão por eixo das máquinas (DIAS JÚNIOR, 2000), o tráfego sobre resíduos culturais (SILVA et al., 2007), o uso de plantas descompactadoras na renovação do canavial (GONÇALVES, et al., 2006), ou, ainda, a definição do nível de compactação prejudicial ao desenvolvimento das culturas (SEVERIANO et al., 2010).

Apesar de o CX em estudo apresentar maior flexibilidade para a colheita mecanizada da cana-de-açúcar, por possuir maior capacidade suporte de carga, salienta-se que esse solo está inserido em relevo movimentado, sugerindo a necessidade de cuidados especiais no seu uso para evitar problemas a sua conservação (SEVERIANO et al., 2009). 
TABELA 3. Valores médios de pressão de preconsolidação $\left(\sigma_{\mathrm{p}}\right)$, determinados após as operações de colheita da cana-de-açúcar, em um Latossolo Vermelho-Amarelo (LVA) e em um Cambissolo Háplico (CX), à profundidade de $0-5 \mathrm{~cm}$, e classificação das amostras, em porcentagem, de acordo com cada região apresentada na Figura 4. Average values of preconsolidation pressure $\left(\sigma_{p}\right)$, determined after the harvesting operations of sugarcane, on a Red-Yellow Latosol (LVA) and a Haplic Cambisol (CX), at 0-5 cm depth, and samples classification, in percentage, according to each region shown in figure 4.

\begin{tabular}{|c|c|c|c|c|c|c|c|c|}
\hline \multirow{3}{*}{ Região } & \multicolumn{3}{|c|}{ Mecanizada } & \multirow{2}{*}{$\frac{\text { Manual }}{3 / 2006}$} & \multicolumn{3}{|c|}{ Mecanizada } & \multirow{2}{*}{$\begin{array}{c}\text { Manual } \\
3 / 2006\end{array}$} \\
\hline & $11 / 2005$ & 3/2006 & $8 / 2006$ & & $11 / 2005$ & $3 / 2006$ & $8 / 2006$ & \\
\hline & \multicolumn{4}{|c|}{ 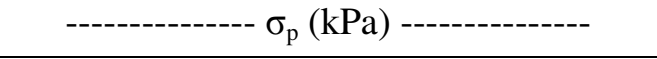 } & \multicolumn{4}{|c|}{-------------- (\%) -------------- } \\
\hline \multicolumn{9}{|c|}{------------------ LVA ------------------ } \\
\hline $\begin{array}{l}\text { a. Com } \\
\text { compactação }\end{array}$ & $256^{3}$ & $265^{2}$ & - & - & 33 & 100 & 0 & 0 \\
\hline $\begin{array}{l}\text { b. Com tendência } \\
\text { a compactar }\end{array}$ & $162^{4}$ & - & $292^{2}$ & $59^{2}$ & 67 & 0 & 100 & 100 \\
\hline $\begin{array}{l}\text { c. Sem } \\
\text { compactação }\end{array}$ & - & - & - & - & 0 & 0 & 0 & 0 \\
\hline \multicolumn{9}{|c|}{----------------- CX ------------------ } \\
\hline $\begin{array}{l}\text { a. Com } \\
\text { compactação }\end{array}$ & $326^{3}$ & $292^{5}$ & - & - & 33 & 50 & 0 & 0 \\
\hline $\begin{array}{l}\text { b. Com tendência } \\
\text { a compactar }\end{array}$ & $266^{4}$ & $246^{5}$ & $332^{2}$ & 140 & 67 & 50 & 100 & 100 \\
\hline $\begin{array}{l}\text { c. Sem } \\
\text { compactação }\end{array}$ & - & - & - & - & 0 & 0 & 0 & 0 \\
\hline
\end{tabular}

\section{CONCLUSÕES}

O Cambissolo Háplico apresentou maior resistência à compactação em relação ao Latossolo Vermelho-Amarelo.

A colheita mecanizada da cana-de-açúcar, mesmo realizada na zona de friabilidade, pode provocar compactação adicional do solo.

Para as condições do estudo, o corte manual da cana-de-açúcar não promove compactação adicional nos solos estudados.

\section{REFERÊNCIAS}

CAMILOTTI, F.; ANDRIOLI, I.; DIAS, F.L.F.; CASAGRANDE, A.A.; SILVA, A.R.; MUTTON, M.A.; CENTURION, J.F. Efeito prolongado de sistemas de preparo do solo com e sem cultivo de soqueira de cana crua em algumas propriedades físicas do solo. Engenharia Agrícola, Jaboticabal, v.25, n.1, p.189-198, 2005.

CENTURION, J.F.; ANDRIOLI, I. Regime hídrico de alguns solos de Jaboticabal. Revista Brasileira de Ciência do Solo, Viçosa - MG, v.24, n.4, p.701-709, 2000.

DIAS JÚNIOR, M.S. Compactação do solo. In: NOVAIS, R.F.; ALVAREZ, V.H.V.; SCHAEFER, C.E.G.R. Tópicos em ciência do solo. Viçosa - MG: UFV, 2000. v.1, p.55-94.

DIAS JÚNIOR, M.S. Compression of three soils under long-term tillage and wheel traffic. 1994. 114 f. Thesis (Ph.D. in Crop and Soil Science) - Michigan State University, East Lansing, 1994.

DIAS JÚNIOR, M.S.; FONSECA, S.; ARAÚJO JÚNIOR, C.F.; SILVA, A.R. Soil compaction due to forest harvest operations. Pesquisa Agropecuária Brasileira, Brasília, v.42, n.2, p.257-264, 2007. 
DIAS JÚNIOR, M.S.; LEITE, F.P.; LASMAR JÚNIOR, E.; ARAÚJO JÚNIOR, C.F. Traffic effects on the soil preconsolidation pressure due to eucalyptus harvest operations. Scientia Agrícola, Piracicaba, v.62, n.3, p.248-255, 2005.

DIAS JÚNIOR, M.S.; PIERCE, F.J. A simple procedure for estimating preconsolidation pressure from soil compression curves. Soil Technology, Lansing, v.8, n.2, p.139-151, 1995.

DOURADO-NETO, D.; NIELSEN, D.R.; HOPMAN, J.W.; REICHARDT, K.; BACCHI, O.O.S; LOPES, P.P. Soil water retention curve (SWRC). Version 3.0. Piracicaba, 2001. Software.

EMBRAPA. EMPRESA BRASILEIRA DE PESQUISA AGROPECUÁRIA. Manual de métodos de análises de solo. 2.ed. Rio de Janeiro: Ministério da Agricultura e do Abastecimento, 1997. $212 \mathrm{p}$.

EMBRAPA. EMPRESA BRASILEIRA DE PESQUISA AGROPECUÁRIA. Sistema brasileiro de classificação de solos. 2.ed. Rio de Janeiro: Ministério da Agricultura e do Abastecimento, 2006. $306 \mathrm{p}$.

GENUCHTEN, M.T.H. van A closed-form equation for predicting the hydraulic conductivity of unsaturated soils. Soil Science Society American Journal, Madison, v.44, p.892-898, 1980.

GONÇALVES, W.G.; JIMENEZ, R.L.; ARAÚJO FILHO, J.V.; ASSIS, R.L.; SILVA, G.P.; PIRES, F.R. Sistema radicular de plantas de cobertura sob compactação do solo. Engenharia Agrícola, Jaboticabal, v.26, n.1, p.67-75, 2006.

HORII, J. A cana-de-açúcar como matéria-prima. Visão Agrícola, Piracicaba, p.88-93, 2004.

KONDO, M.K.; DIAS JÚNIOR, M.S. Compressibilidade de três Latossolos em função da umidade e uso. Revista Brasileira de Ciência do Solo, Viçosa - MG, v.23, n.2, p.211-218, 1999.

LEBERT, M.; HORN, R. A method to predict the mechanical strength of agricultural soils. Soil \& Tillage Research, Amsterdam, v.19, n.2-3, p.275-286, 1991.

OLIVEIRA, G.C.; DIAS JÚNIOR, M.S.; RESCK, D.V.S.; CURI, N. Alterações estruturais e comportamento compressivo de um Latossolo Vermelho distrófico argiloso sob diferentes sistemas de uso e manejo. Pesquisa Agropecuária Brasileira, Brasília, v.38, n.2, p.291-299, 2003.

OLIVEIRA, G.C.; DIAS JÚNIOR, M.S.; RESCK, D.V.S.; CURI, N. Caracterização química e físico-hídrica de um Latossolo Vermelho após vinte anos de manejo e cultivo do solo. Revista Brasileira de Ciência do Solo, Viçosa - MG, v.28, n.2, p.327-336, 2004.

PANKHURST, C.E.; MAGAREY, R.C.; STIRLING, G.R.; BLAIR, B.L.; BELL, M.J.; GARSIDE, A.L. Management practices to improve soil health and reduce the effects of detrimental soil biota associated with yield decline of sugarcane in Queensland, Australia. Soil \& Tillage Research, Amsterdam, v.72, n.2, p.125-137, 2003.

REINERT, D.J.; REICHERT, J.M. Coluna de areia para medir a retenção de água no solo protótipos e teste. Ciência Rural, Santa Maria, v.36, n.6, p.1.931-1.935, 2006.

SANTOS, R.D.; LEMOS, R.C.; SANTOS, U.G.; KER, J.C.; ANJOS, L.H.C. Manual de descrição e coleta de solo no campo. 5.ed. Viçosa - MG: Sociedade Brasileira de Ciência do Solo, 2005. 92 p.

SEVERIANO, E.C.; OLIVEIRA, G.C.; CURI, N.; DIAS JÚNIOR, M.S. Potencial de uso e qualidade estrutural de dois solos cultivados com cana-de-açúcar em Goianésia, GO. Revista Brasileira de Ciência do Solo, Viçosa - MG, v.33, n.1, p.159-168, 2009.

SEVERIANO, E.C.; OLIVEIRA, G.C.; DIAS JÚNIOR, M.S.; CASTRO, M.B.; OLIVEIRA, L.F.C.; COSTA, K.A.P. Compactação de solos cultivados com cana-de-açúcar: II - quantificação das restrições às funções edáficas do solo em decorrência da compactação prejudicial. Engenharia Agrícola, Jaboticabal, v.30, n.3, p.414-423, 2010. 
SILVA, A.R.; DIAS JÚNIOR, M.S.; LEITE, F.P. Camada de resíduos florestais e pressão de preconsolidação de dois latossolos. Pesquisa Agropecuária Brasileira, Brasília, v.42, n.1, p.89-93, 2007.

SILVA, R.B.; LIMA, J.M.; DIAS JÚNIOR, M.S. Efeito da adsorção de fosfato em parâmetros físicos e na compressibilidade de solos tropicais. Revista Brasileira de Ciência do Solo, Viçosa MG, v.23, n.2, p.219-226, 1999.

SNEDECOR, G.W.; COCHRAN, W.G. Statistical methods. 8th.ed. Ames: Iowa State University, 1989. $503 \mathrm{p}$.

SOUZA, Z.M.; PRADO, R.M.; PAIXÃO, A.C.S.; CESARIN, L.G. Sistemas de colheita e manejo da palhada de cana-de-açúcar. Pesquisa Agropecuária Brasileira, Brasília, v.40, n.3, p.271-278, 2005.

TAYLOR, D.W. Fundamentals of soil mechanics. New York: J. Wiley, 1948. 700p.

VEIGA, M.; HORN, R; REINERT, D.J.; REICHERT, J.M. Soil compressibility and penetrability of an Oxisol from southern Brazil, as affected by long-term tillage systems. Soil \& Tillage Research, Amsterdam, v.92, n.1-2, p.104-113, 2007. 